\title{
Cerium(III)-promoted synthesis of methoximes and preliminary results of their activity against phytopathogenic fungi
}

\author{
Iván Cortés, ${ }^{a}$ Melina G. Di Liberto, ${ }^{b}$ Marcos G. Derita, ${ }^{*, b, c}$ Teodoro S. Kaufman ${ }^{a}$ and Andrea B. J. Bracca*a \\ anstituto de Química Rosario IQUIR (CONICET-UNR), and Facultad de Ciencias Bioquímicas y \\ Farmacéuticas, Universidad Nacional de Rosario (UNR), Suipacha 531 (2000) Rosario, Argentina \\ ${ }^{b}$ Farmacognosia, Facultad de Ciencias Bioquímicas y Farmacéuticas-Universidad Nacional de Rosario, \\ Suipacha 531, S2002LRK Rosario, Argentina \\ ${ }^{c}$ CONICET, Facultad de Ciencias Agrarias-Universidad Nacional del Litoral, Kreder 2805, S3080HOF, \\ Esperanza, Argentina \\ E-mails: mgderita@hotmail.com; bracca@iquir-conicet.gov.ar
}

\begin{abstract}
The reaction between aromatic and aliphatic aldehydes and ketones with methoxylamine is promoted by cerium chloride. The antifungal activity of some methoxime derivatives against five postharvest phytopathogenic fungi, was examined, employing imazalil and carbendazim as positive controls, and the preliminary results are discussed. The target fungi were Rhizopus stolonifer, Botrytis cinerea, Penicillium digitatum, Penicillium italicum and Monilinia fructicola. These phytopathogens affect fruits worldwide, causing relevant economic damage. In all cases, minimum inhibitory concentrations and minimum fungicidal concentrations were obtained. Despite most of the simple compounds resulted inactive, preliminary results suggest that certain compounds display a structure-dependent activity which correlates with the length of the substituent attached to the oxime $\mathrm{sp}^{2}$ carbon.
\end{abstract}

Keywords: $\mathrm{CeCl}_{3}$-promoted reaction; methoximation; antifungal activity; postharvest phytopathogenic fungi

\section{Introduction}

Phytopathogenic fungi cause important economic losses, due to crop yield reduction as well as through food contamination which results in diminished product quality and safety. ${ }^{1}$ Rhizopus stolonifer (Ehrenb.: Fr.) Vuill is a fast-growing phytopathogen, which causes the black mold rot in a wide variety of hosts and is considered as one of the most devastating threats during the postharvest stage. ${ }^{2 a}$ Botrytis cinerea (Pers.: Fr.) is a ubiquitous pathogen, responsible for the botrytis bunch rot, which causes heavy losses to table and wine grapes. ${ }^{2 b}$ On the other hand, Monilinia fructicola (G. Wint.) Honey is at the 
root of the brown rot, a serious disease that affects the quality of peaches resulting in heavy production losses. ${ }^{2 c}$ Some strains of Penicillium are also damage-causing agents especially in citrus production. Since regulations on the use of new and existing fungicides are becoming more and more stringent, it urges to identify and develop new chemical entities with antifungal properties.

Oxime esters, have been shown to be bioactive and were used in the experimental molecular design of antifungals (Figure 1). Other examples include the commercial insecticide aldicarb and the herbicide trifopsime. ${ }^{3}$ The oxime ether moiety is also an important structural motif found in a wide variety of physiologically relevant compounds. This functional group is widespread among approved crop-protecting agents, such as the synthetic strobilurins trifloxastrobin and fluoxastrobin, for conferring them valuable selectivity in their biocidal properties. ${ }^{4 a}$ Oxime ethers are also frequently present in the patent literature, being broadly used as intermediates in the chemical industry and in synthetic organic chemistry. ${ }^{4 b}$ Oxime ethers have been employed as precursors of other functional groups, such as alkoxy-amides/lactams, ${ }^{5 \mathrm{a}}$ nitriles ${ }^{5 \mathrm{~b}}$ and amidines. ${ }^{5 \mathrm{c}}$

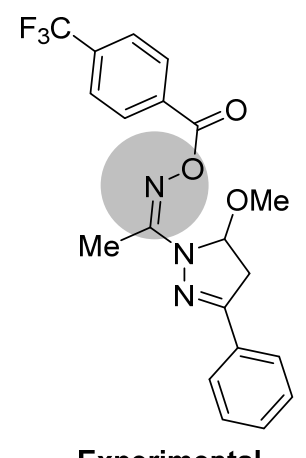

Experimental antifungal agent
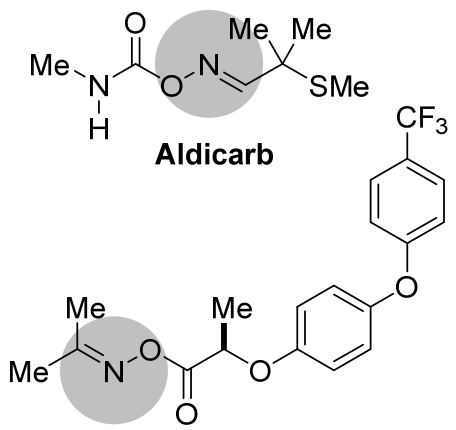

Trifopsime

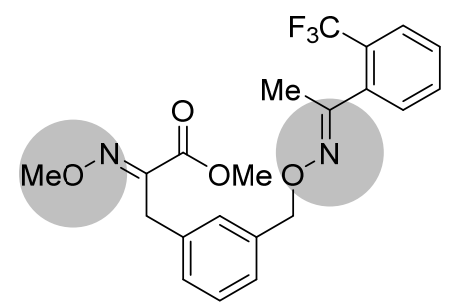

Trifloxastrobin

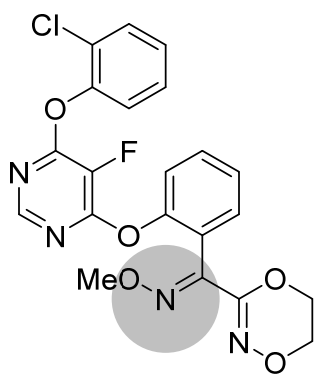

Fluoxastrobin

Figure 1. Examples of synthetic experimental and commercial antifungal agents which are oximes and/or carry the methoxime motif.

The methoximes are a special group among the oxime ethers, which have been synthesized by reaction of aldehydes or ketones with methoxylamine ${ }^{6 \mathrm{a}}$ in (hydro)alcoholic media, pyridine ${ }^{6 \mathrm{~b}, \mathrm{c}}$ or chlorinated solvents ${ }^{6 \mathrm{~d}}$ usually under refluxing conditions to improve yields.

In view of these precedents, we have optimized a catalytic approach toward the preparation of methoximes ${ }^{7}$ and studied their activity against five phytopathogenic fungi. The preliminary results of this study are presented here.

\section{Results and Discussion}

The conditions for the methoximation were optimized in an OVAT (one variable at a time) fashion, with regards to the promoter, solvent, amount of methoxylamine 
hydrochloride and temperature (Scheme 1). The optimized protocol demanded the use of $\mathrm{MeONH}_{2} . \mathrm{HCl}$ (1.5 equiv.) in the presence of $\mathrm{NaOAc}\left(1.5\right.$ equiv.) and $\mathrm{CeCl}_{3} .7 \mathrm{H}_{2} \mathrm{O}(5$ $\mathrm{mol} \%$ ) in $\mathrm{EtOH}$ at $50^{\circ} \mathrm{C}$. This condition demonstrated to be mild enough and compatible with sensitive compounds, while remaining a highly discriminating condition against the non-catalyzed process.

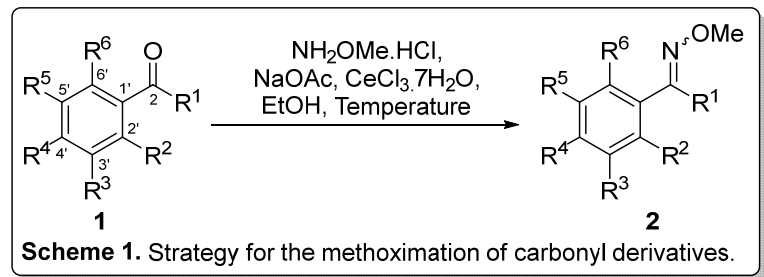

The scope of the optimized methodology was explored (Table 1) with various aromatic (entries 1-10) and aliphatic (entries 11-16) ketones and aldehydes, carrying different substituents and substitution patterns. Generally, very good to excellent yields were obtained, observing that in general the aldehydes (entries 1,6,7 and 11) reacted at a faster pace.

No significant effects were detected, related to either electron withdrawing (entry 4) or electron donating (entries 1-2 and 5-10) groups attached to different positions of the aromatic ring, but the nitro derivatives reacted at a lower rate. In addition, the reaction of ortho-substituted carbonyls (entries 1,2 and 5-7) proceeded without substantial loss of performance, except when two substituents were present (entry 10). Bulkier aromatic ketones also exhibited longer reaction times (entries 2 and 3 ).

Table 1. Study of the scope of the catalytic methoximation.

\begin{tabular}{|c|c|c|c|c|c|c|c|}
\hline $\begin{array}{c}\text { Entry } \\
\mathbf{N}^{\circ}\end{array}$ & Compound & $\begin{array}{c}\text { Time } \\
\text { (h) }\end{array}$ & Yield (\%) & Entry $\mathbf{N}^{\circ}$ & Compound & Time (h) & Yield (\%) \\
\hline 1 & ${ }^{\text {Noo }}$ & 0.4 & 97 & 9 & & 1 & 84 \\
\hline 2 & & 18 & 89 & 10 & & 72 & 89 \\
\hline 3 & & 24 & 94 & 11 & & 0.6 & 79 \\
\hline 4 & & 2 & 84 & 12 & & 1.3 & 82 \\
\hline 5 & & 12 & 80 & 13 & & 12 & 71 \\
\hline 6 & & 0.4 & 97 & 14 & & 0.4 & 96 \\
\hline 7 & moo, ome Nomo & 0.3 & 92 & 15 & $\begin{array}{c}\text { Me } \\
\text { Me }\end{array}$ & 12 & 72 \\
\hline 8 & & 1.1 & 80 & 16 & & 12 & 58 \\
\hline
\end{tabular}

Ketones displaying ortho hydroxy groups required longer reaction periods, 
presumably as a result of the presence of a hydrogen bond between the phenol and the carbonyl moieties. The transformation also took place in the presence of free phenols and free amines. The reactions of non-aromatic aldehydes confirmed that the transformation is efficient in the presence of some steric hindrance and double bond conjugation. In the latter case, the reaction conditions are mild enough to prevent Michael addition. Further, the transformation was also successful with $\mathrm{NH}_{2} \mathrm{OH}$, does not require the use of anhydrous $\mathrm{CeCl}_{3}$ and is still efficient when run in $\mathrm{EtOH} 96^{\circ}$.

The structures of the methoximes were assessed by their melting points, as well as by infrared and NMR $\left({ }^{1} \mathrm{H}\right.$ and $\left.{ }^{13} \mathrm{C}\right)$ spectroscopy. They were in full agreement with their proposed structures. In many cases mixtures of anti/syn $(E / Z)$ isomeric compounds were obtained, that could not be separated chromatographically. The major products were assigned as the anti-isomers on the basis of comparative analysis of their ${ }^{1} \mathrm{H}$ NMR spectral data.

The reaction mechanism is still unclear, but it seems that the transformation proceeds through a series of steps (Scheme 2), where the oxophilic promoter coordinates with the carbonyl moiety of the aldehyde/ketone (1) to afford the activated intermediate $\boldsymbol{i}$. The latter is more likely to undergo nucleophilic attack by the nitrogen of the methoxylamine than the starting carbonyl derivative, and furnish the intermediate $i$ in a second step.

Next, the intermediate iii is generated though an intramolecular proton transfer. The latter is prone to undergo dehydration with concomitant deprotonation, releasing the methoxime product (2) and regenerating the promoter. Although the stages from $\mathbf{1}$ to iii may be readily reversible under the mild reaction conditions, once compound $\mathbf{2}$ is formed, it is less likely that it could revert to the starting carbonyl derivative (1) under the

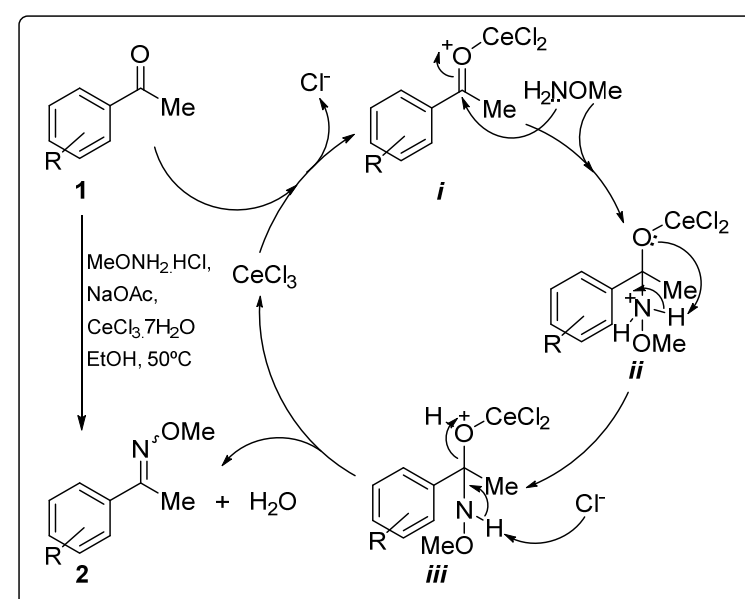

Scheme 2. Proposed reaction mechanism for the $\mathrm{CeCl}_{3} \cdot 7 \mathrm{H}_{2} \mathrm{O}-$ promoted methoximation of aromatic aldehydes and ketones. same conditions, due to the relative hydrolytic stability of the oxime ethers. ${ }^{8}$

Some of the synthesized methoximes were submitted to a preliminary round of biological tests for their activity against five strains of postharvest phytopathogenic fungi, including $R$. stolonifer, B. cinerea, $P$. digitatum, $P$. italicum and $M$. fructicola. These phytopathogens affect fruits worldwide, and cause substantial economic damage. As shown in Table 2, minimum inhibitory concentrations (MIC) and minimum fungicidal concentrations (MFC) were obtained for the tested compounds. 
Table 2. Preliminary screening of activities against five phytopatogenic fungi.

\begin{tabular}{|c|c|c|c|c|c|c|c|c|c|c|c|}
\hline \multirow{2}{*}{$\begin{array}{l}\text { Entry } \\
\mathbf{N}^{\circ}\end{array}$} & \multirow{2}{*}{ Compound } & \multicolumn{5}{|c|}{ MIC } & \multicolumn{5}{|c|}{ MFC } \\
\hline & & P. digitatum & \begin{tabular}{|l|} 
P. italicum \\
\end{tabular} & B. cinerea & M. fructicola & R. stolonifer & P. digitatum & P. italicum & B. cinerea & M. fructicola & $\begin{array}{l}\text { R. stolonifer } \\
\end{array}$ \\
\hline 1 & & $>250$ & $>250$ & 125 & 250 & $>250$ & $>250$ & $>250$ & 125 & $>250$ & $>250$ \\
\hline 2 & & 125 & 250 & 125 & 62.5 & 62.5 & $>250$ & $>250$ & 125 & $>250$ & 125 \\
\hline 3 & & $>250$ & $>250$ & 125 & $>250$ & $>250$ & $>250$ & $>250$ & 250 & $>250$ & $>250$ \\
\hline 4 & & 62.5 & 62.5 & $>250$ & 62.5 & 15.6 & $>250$ & $>250$ & $>250$ & $>250$ & 62.5 \\
\hline 5 & & $>250$ & 250 & 250 & 125 & 125 & $>250$ & $>250$ & $>250$ & $>250$ & $>250$ \\
\hline 6 & & 250 & 250 & 125 & 125 & 250 & $>250$ & $>250$ & $>250$ & $>250$ & $>250$ \\
\hline 7 & & $>250$ & $>250$ & 250 & $>250$ & 250 & $>250$ & $>250$ & $>250$ & $>250$ & $>250$ \\
\hline 8 & & $>250$ & $>250$ & $>250$ & $>250$ & $>250$ & $>250$ & $>250$ & $>250$ & $>250$ & $>250$ \\
\hline 9 & & $>250$ & $>250$ & $>250$ & $>250$ & $>250$ & $>250$ & $>250$ & $>250$ & $>250$ & $>250$ \\
\hline 10 & & $>250$ & $>250$ & $>250$ & $>250$ & $>250$ & $>250$ & $>250$ & $>250$ & $>250$ & $>250$ \\
\hline 11 & & $>250$ & $>250$ & $>250$ & $>250$ & $>250$ & $>250$ & $>250$ & $>250$ & $>250$ & $>250$ \\
\hline 12 & & $>250$ & $>250$ & $>250$ & $>250$ & $>250$ & $>250$ & $>250$ & $>250$ & $>250$ & $>250$ \\
\hline 13 & & $>250$ & $>250$ & $>250$ & $>250$ & $>250$ & $>250$ & $>250$ & $>250$ & $>250$ & $>250$ \\
\hline 14 & & $>250$ & $>250$ & $>250$ & $>250$ & $>250$ & $>250$ & $>250$ & $>250$ & $>250$ & $>250$ \\
\hline 15 & & $>250$ & $>250$ & $>250$ & $>250$ & $>250$ & $>250$ & $>250$ & $>250$ & $>250$ & $>250$ \\
\hline 16 & & $>250$ & $>250$ & $>250$ & $>250$ & $>250$ & $>250$ & $>250$ & $>250$ & $>250$ & $>250$ \\
\hline 17 & & $>250$ & $>250$ & $>250$ & $>250$ & $>250$ & $>250$ & $>250$ & $>250$ & $>250$ & $>250$ \\
\hline 18 & & $>250$ & $>250$ & 250 & $>250$ & $>250$ & $>250$ & $>250$ & $>250$ & $>250$ & $>250$ \\
\hline
\end{tabular}

It was observed that most of the simple compounds resulted inactive (MIC and MFC $>250 \mu \mathrm{g} / \mathrm{mL}$ ) against all the targets. However, it was noticed that the compounds of entries 1-5 displayed some degree of activity against some of the phytopathogens evaluated. Notably, it was observed that phenol of entry 1 displayed activity against $B$. cinerea (MIC $=\mathrm{MFC}=125 \mu \mathrm{g} / \mathrm{mL}$ ), which disappeared when the phenol moiety was blocked (entry 7). 
The methoxime of benzophenone (entry 3 ) was also slightly active against B. cinerea $(\mathrm{MIC}=125 \mu \mathrm{g} / \mathrm{mL}$ ), whereas the ortho-nitrophenol of entry 4 exhibited a wider profile, with MIC values of $62.5 \mu \mathrm{g} / \mathrm{mL}$ against $P$. digitatum, $P$. italicum and $M$. fructicola, and of $15.6 \mu \mathrm{g} / \mathrm{mL}$ against $R$. stolonifer, being fungicide only against the latter $(\mathrm{MFC}=125$ $\mu \mathrm{g} / \mathrm{mL})$.

On the other hand, the homologous series of compounds tested in runs 2, 5 and 6 exhibited inhibitory activity against 2-4 fungi (P. digitatum, $R$. stolonifer, B. cinerea and/or M. fructicola) with MIC values down to $62.5 \mu \mathrm{g} / \mathrm{mL}$. Notably, the propiophenone derivative (entry 2) exhibited the best profile, being also fungicide against $R$. stolonifer and B. cinerea $(\mathrm{MFC}=125 \mu \mathrm{g} / \mathrm{mL})$.

Since the observed antifungal activities seemed to be somehow related to the length of the substituent attached to the oxime $\mathrm{sp}^{2}$ carbon the ketones were tested against the five fungal strains (entries 17 and 18), where they proved to be inactive, ruling out the presence of phenolic hydroxyls as the main cause of bioactivity.

\section{Experimental section}

\section{General experimental details}

The reactions were executed with oven-dried glassware and freshly distilled anhydrous solvents. The reactions were monitored by TLC, where the spots were detected by exposure to $254 \mathrm{~nm} \mathrm{UV} \mathrm{light,} \mathrm{and} \mathrm{by} \mathrm{spraying} \mathrm{with} \mathrm{ethanolic} p$-anisaldehyde/ $/ \mathrm{H}_{2} \mathrm{SO}_{4}$. All new compounds gave single spots on TLC plates run in different solvent systems. The flash column chromatographies were run with silica gel $60 \mathrm{H}$ (particle size 63-200 $\mu \mathrm{m}$ ), eluting under positive pressure with hexane-EtOAc mixtures, and employing gradient of solvent polarity techniques.

The melting points were measured on an Ernst Leitz Wetzlar model 350 hot-stage microscope and are informed uncorrected. The FT-IR spectra were acquired with a Shimadzu Prestige 21 spectrophotometer, with the samples as thin films held between $\mathrm{NaCl}$ cells or prepared as solid dispersions in $\mathrm{KBr}$ disks. The NMR spectra were recorded in $\mathrm{CDCl}_{3}$ on a Bruker Avance 300 spectrometer, at $300.13\left({ }^{1} \mathrm{H}\right)$ and $75.48\left({ }^{13} \mathrm{C}\right) \mathrm{MHz}$. Highresolution mass spectra were obtained from UMYMFOR (Buenos Aires, Argentina) with a Bruker MicroTOF-Q II instrument. Detection of the ions was performed in electrospray ionization, positive ion mode.

\section{General procedure for the syntheses of the methoximes}

A stirred mixture of the aldehyde or ketone $(0.30 \mathrm{mmol}), \mathrm{MeONH} 2 . \mathrm{HCl}(37.5 \mathrm{mg}$, $0.45 \mathrm{mmol}, 1.5$ equiv.) and anhydrous $\mathrm{NaOAc}(37 \mathrm{mg}, 0.45 \mathrm{mmol}, 1.5$ equiv.) in absolute 
EtOH $(2.5 \mathrm{~mL})$ was treated with $\mathrm{CeCl}_{3} .7 \mathrm{H}_{2} \mathrm{O}(5.6 \mathrm{mg}, 5 \mathrm{~mol} \%)$. The reaction was heated to $50^{\circ} \mathrm{C}$ in a test tube, and progress of the reaction was monitored by TLC. After completion, brine $(10 \mathrm{~mL})$ was added and the products were extracted with EtOAc $(3 \times 10 \mathrm{~mL})$. The combined organic layers were dried over $\mathrm{MgSO}_{4}$ and concentrated under reduced pressure. The residue was purified by column chromatography.

\section{Compound characterization}

4-[(1E)-N-Methoxyethanimidoyl]-2-nitrophenol.- White solid; m.p.: $89-92^{\circ} \mathrm{C}$; yield: $84 \%$. IR (KBr, v): 3242, 2940, 1628, 1537, 1323, 1312, 1177, 1040, 883, 845, 764, 687 and $602 \mathrm{~cm}^{-1} .{ }^{1} \mathrm{H}$ NMR: 2.21 (s, 3H, Me), 3.94 (s, 3H, N-OMe), $7.14(\mathrm{~d}, J=8.8,1 \mathrm{H}$, H-5'), 8.0 (dd, $J=2.3$ and 8.8, 1H, H-6'), 8,30 (d, $J=2.3,1 \mathrm{H}, \mathrm{H}-2^{\prime}$ ) and 10.65 (s, $1 \mathrm{H}$, OH). ${ }^{13} \mathrm{C}_{\mathrm{NMR}} 12.0(\mathrm{Me}), 62.2$ (N-OMe), 120.1 (C-5'), 122.2 (C-2'), 129.4 (C-1'), 133.3 (C-6'), 134.9 (C-3'), 151.7 (C-1) and 155.5 (C-4'). EI-MS (m/z, \%): $210\left(\mathrm{M}^{+}, 88\right), 179$ (73) and $133(100)$.

4-[(1E)- $N$-Methoxypropanimidoyl]benzene-1,3-diol.- Yellowish oil; yield: $89 \%$. IR (film, v): 3379, 2978, 2938, 1703, 1634, 1614, 1520, 1454, 1250, 1047, 970, 891, 851 and $743 \mathrm{~cm}^{-1} .{ }^{1} \mathrm{H}$ NMR: 1.17 (t, $J=7.6,3 \mathrm{H}, \mathrm{H}-3$ ), 2.77 (q, $\left.J=7.6,2 \mathrm{H}, \mathrm{H}-2\right), 3.96$ (s, 3H, NOMe), 5.67 (s, 1H), 6.41 (dd, $J=2.6$ and 8.6, 1H, H-4'), 6.46 (d, $\left.J=2.5,1 \mathrm{H}, \mathrm{H}-2^{\prime}\right), 7.27$ (d, $\left.J=8.5,1 \mathrm{H}, \mathrm{H}-5^{\prime}\right)$ and $11.73(\mathrm{~s}, 1 \mathrm{H}) .{ }^{13} \mathrm{C}$ NMR: $11.4(\mathrm{C}-3), 18.8(\mathrm{Me}), 62.3(\mathrm{~N}-\mathrm{OMe})$, 103.9 (C-2'), 107.1 (C-4'), 110.7 (C-6'), 128.8 (C-5'), 157.9 (C-3'), 160.0 (C-1') and 163.2 (C-1). EI-MS (m/z, \%): $195\left(\mathrm{M}^{+}, 83\right), 180\left[(\mathrm{M}-15)^{+}, 1\right], 164$ (33), 135 (100) and 108 (57). HRMS (ESI-TOF, $m / z)$ : obsd. 196.0970; $\mathrm{C}_{10} \mathrm{H}_{14} \mathrm{NO}_{3}\left[(\mathrm{M}+\mathrm{H})^{+}\right]$requires 196.0974 .

\section{Antifungal studies}

The microorganisms and media have been previously detailed, and the susceptibility tests were carried out as reported previously. ${ }^{9}$

\section{Conclusions}

We have developed and optimized an efficient $\mathrm{CeCl}_{3} .7 \mathrm{H}_{2} \mathrm{O}$-based catalytic method for the methoximation of aldehydes and ketones under mild conditions. The reaction takes place with a sustainable solvent such as ethanol and an eco-friendly promoter. The catalytic system is robust, and applicable to a variety of aldehydes and ketones, being tolerant to steric demand as well as to electron poor and electron rich substrates.

Some methoximes obtained by application of this protocol were studied as potential agents against five postharvest phytopathogenic fungi. The presented preliminary results indicate that only a handful of compounds were active and that some simple structureactivity conclusions may be drawn in the case of the 2,4-dihydroxy derivatives. 


\section{Acknowledgements}

The authors gratefully acknowledge Consejo Nacional de Investigaciones Científicas

y Técnicas (CONICET, PUE IQUIR-2016 and PIP 524), Agencia Nacional de Promoción Científica y Tecnológica (ANPCyT, PICT 2014-0445 and PICT 2015-2259) and Agencia Santafesina de Ciencia, Tecnología e Innovación (ASACTeI, institutional grant AC 20150005) for financial support. I. C. and M. G. DL. also thank CONICET for their fellowship.

\section{References}

[1] Plant Pathology in the 21st Century, Vol. 7. Prusky, D.; Gullino, M. L., Eds. Springer, London, UK, 2014.

[2] (a) Bautista-Baños, S.; Bosquez-Molina, E. L.; Barrera-Necha, L. Rhizopus stolonifer (Soft Rot). In: Bautista-Baños, S. (Ed.), Postharvest decay: Control strategies. Elsevier, London, UK, 2014, pp.1-44; (b) Masih, E. I.; Slezack Deschaumes, S.; Marmaras, I.; Barka, E.A.; Vernet, G.; Charpentier, C.; Adholeya, A.; Paul, B. FEMS Microbiol. Lett. 2001, 202, 227-232; (c) Zhu, X. Q.; Chen, X. Y.; Luo, Y.; Guo, L. Y. Plant Pathol. 2005, 54, 575-575.

[3] (a) Liu, X.-H.; Cui, P.; Song, B.-A.; Bhadury, P. S.; Zhu, H.-L.; Wang, S.-F. Bioorg. Med. Chem. 2008, 16, 4075-4082; (b) Ouyang, G.; Chen, Z.; Cai, X.-J.; Song, B.-A.; Bhadury, P. S.; Yang, S.; Jin, L.-H.; Xue, W.; Hu, D.-Y.; Zeng, S. Bioorg. Med. Chem. 2008, 16, 9699-9707.

[4] (a) Benoit, R.; Sauter, H.; Kirstgen, R. Patent EP 498188, 1992; (b) Mirjafary, Z.; Abdoli, M.; Saeidian, H.; Boroon, S.; Kakanejadifard, A. RSC Adv. 2015, 5, 7936179384.

[5] (a) Isshiki, Y.; Kohchi, Y.; Iikura, H.; Matsubara, Y.; Asoh, K.; Murata, T.; Kohchi, M.; Mizuguchi, E.; Tsujii, S.; Hattori, K. Bioorg. Med. Chem. Lett. 2011, 21, 17951801; (b) Anand, N.; Owston, N. A.; Parker, A. J.; Slatford, P. A.; Williams, J. M. J. Tetrahedron Lett. 2007, 48, 7761-7763; (c) Ambhaikar, N. B.; Snyder, J. P.; Liotta D. C. J. Am. Chem. Soc. 2003, 125, 3690-3691.

[6] (a) Gou, Q.; Deng, B.; Qin, J. Chem. Eur. J. 2015, 21, 12586-12591; (b) Ashani, Y.; Silman, I. Hydroxylamines and oximes: Biological properties and potential uses as therapeutic agents. In: The chemistry of hydroxylamines, oximes and hydroxamic acids (Eds.: Rappoport, Z.; Liebman, J. F.), Wiley, Chichester, UK, 2008, pp. 609651; (c) Dubost, E.; Fossey, C.; Cailly, T.; Rault, S.; Fabis, F. J. Org. Chem. 2011, 76, 6414-6420; (d) Langenhan, J. M.; Endo, M. M.; Engle, J. M.; Fukumoto, L. L.; Rogalsky, D. R.; Slevin, L. K.; Fay, L. R.; Lucker, R. W.; Rohlfing, J. R.; Smith, K. R. Carbohydr. Res. 2011, 346, 2663-2676.

[7] Cortés, I.; Kaufman, T. S.; Bracca, A. B. J. RS Open Sci. 2018, 5, 180279.

[8] Neufeldt, S. R.; Sanford, M. S. Org. Lett. 2012, 15, 46-49.

[9] Pergomet, J. L.; Di Liberto, M. G.; Derita, M. G.; Bracca, A. B. J.; Kaufman, T. S. Fitoterapia 2018, 125, 98-105. 